\title{
Dilemma in Diagnosis-Huge Preauricular Sinus Mimicking Parotid Tumor
}

\author{
Ling Xiu Ngui*1, Shashi Gopalan² and Muhammad Nasri Abu Bakar ${ }^{3}$ \\ ${ }^{1}$ Department of ORL-HNS Medical officer, Sibu Hospital, Malaysia \\ ${ }^{2}$ Department of ORL-HNS, Surgeon, Sibu Hospital, Malaysia
}

Received: December 06, 2017; Published: December 11, 2017

*Corresponding author: Ling Xiu Ngui, Department of Otorhinolaryngology, Head and Neck Surgery, Sibu Hospital KM 5 1/2, Jalan Ulu Oya, 96000 Sibu, Sarawak, Malaysia

\begin{abstract}
Objective: This paper reports a case of huge preauricular sinus mimicking parotid tumour to highlight the difficulty in obtaining a correct diagnosis.

Background and Case Report: This case describes a 51-year-old gentleman who presented with a huge, soft and painless swelling over left parotid region which was progressively increasing in size over two years. The swelling appeared to push the left ear lobule upward and on palpation, the swelling did not go beyond the zygomatic arch. Fine needle aspiration was unsatisfactory. Ultrasonography scan showed left parotid tumour. The diagnosis of preauricular sinus was made only upon excision of the mass under general anaesthesia. Post operatively, the recovery was good and there was no complication.
\end{abstract}

Conclusion: Though it is extremely rare, preauricular sinus should be considered as a differential diagnosis of painless soft parotid swelling. Keywords: Preauricular sinus; Parotid

\section{Introduction}

Preauricular sinus is a benign congenital malformation of the preauricular soft tissue, first described by Van Heusinger in 1864 [1]. Preauricular sinuses are formed from incomplete or defective fusion of the six auditory hillocks during embryological development of auricle at sixth week of gestation. We would like to report a case of a huge preauricular sinus as a rare differential diagnosis of a parotid swelling.

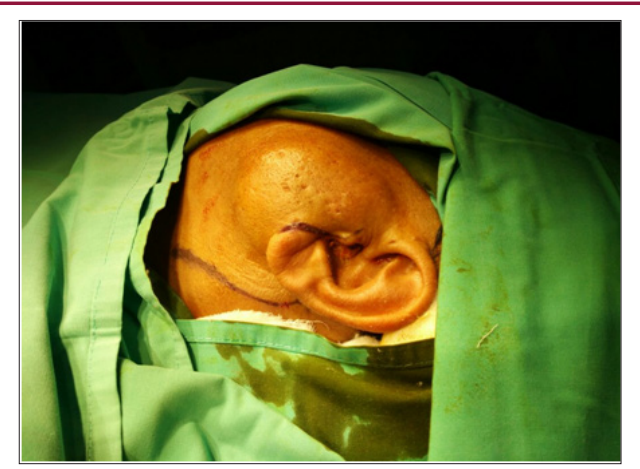

Figure 1: Left parotid swelling measuring $7 \mathrm{~cm} \times 5 \mathrm{~cm}$. Note the presence of small pit over ascending limb of helix (black arrow).

\section{Case Report}

A 51-year-old gentleman presented to us with a painless swelling over the left parotid region for duration of two years. The swelling gradually increased in size and there were no episodes of inflammation or infection of the swelling. He had no significant past medical or surgical history. Examination revealed a $7 \times 5 \mathrm{~cm}$ swelling over left parotid region, elevating the ear lobe and with multiple pits all over the swelling and cheek region (Figure 1). On palpation, the swelling was doughy in consistency, non-tender. His facial nerve function was grossly normal. There were no palpable neck nodes. Fine needle aspiration for cytology was performed of the swelling which was unsatisfactory. Ultrasonography of the left parotid swelling showed a well-defined, homogenous, hypoechoic mass at the left parotid gland measuring $7.3 \times 5.0 \times 2.0 \mathrm{~cm}$, with no internal vascularity seen. A differential diagnosis of pleomorphic adenoma was made. With the above clinical and imaging correlation, patient was planned for left superficial parotidectomy. Left modified Bailey incision was made. A preauricular cyst with sinus tract was revealed. (Figures $2 \& 3$ ) The surrounding skin was adhered to the swelling which was able to be dissected of by meticulous dissection. The preauricular cyst with sinus tract was completely excised with 
preservation of left parotid gland. Patient was discharged day one post operatively with no complication. Patient was well in three months of follow-up with no signs of recurrence.

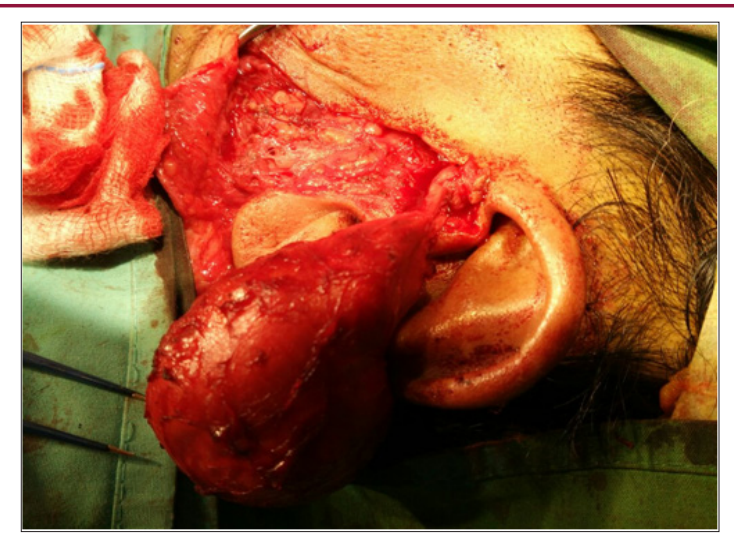

Figure 2: Complete excision of the mass with attachment to the preauriclar sinus opening.

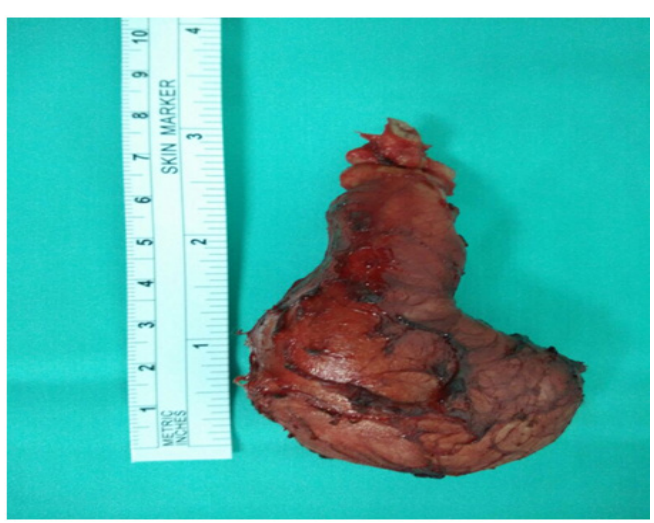

Figure 3: The excised preauricular sinus mass measuring about $7 \times 5 \mathrm{~cm}$.

\section{Discussion}

Preauricular sinus has an incidence of 0.1 to $0.9 \%$ in Western populations and a higher incidence of $4 \%$ and $10 \%$ among Blacks and Orientals [2]. This condition can occur either sporadically or via inheritance. Unilateral preauricular sinus is more common than bilateral. Over $50 \%$ of preauricular sinus cases are unilateral and likely to be sporadic while in 25 to $50 \%$ of cases, preauricular sinuses are bilateral and are more likely to be hereditary [3]. Preauricular sinus can usually be noticed as a small pit adjacent to the anterior margin of the ascending limb of the helix, rarely along the posterosuperior margin of the helix, tragus or lobule. Most of the preauricular sinus are asymptomatic and do not require any treatment. Patient may present with persistent discharge from the preauricular sinus or signs of acute infection of sinus tract. In our patient, there was presence of unilateral preauricular sinus pit over the anterior margin of ascending limb of left helix, with multiple pits surrounding the overlying skin of the swelling. However, this did not give rise to any discharge.

Infected preauricular sinus requires administration of antibiotics. Incision and drainage is necessary in the presence of abscess. Surgical excision of the sinus tract is then carried out after resolution of the acute infection to prevent recurrent preauricular sinus infection. Incomplete excision of sinus tract leads to recurrence of preauricular sinus. Recurrence rate ranged from 22 to $42 \%$ has been reported in cases where preauricular sinus is excised with traditional method without any aid for tract delineation or visualisation [4]. Robert J et al reported a new inside-out technique for excision of preauricular sinus where no recurrence was noted [5]. Gan EC et al. reported a low recurrence rate of $2.4 \%$ by performing excision of preauricular sinus under microscope guidance and under methylene blue and probe guidance [4]. From our literature review, there were no reported cases of preauricular sinus presenting as parotid swelling. In view of a huge and soft swelling over left parotid region, the differentials include sebaceous cyst and benign parotid neoplasm. The possibility of left preauricular sinus was never thought of as clinically and ultrasonographically looked more like a mass arising from parotid gland.

\section{Conclusion}

In conclusion, though it is extremely rare, preauricular sinus should be considered as a differential diagnosis of painless soft parotid swelling. Computed tomography scan might assist in differentiating a huge preauricular sinus which mimics a parotid tumour. Complete excision is deemed necessary to prevent recurrence.

\section{Summary}

a) Preauricular sinus is formed from incomplete or defective fusion of the six auditory hillocks during embryological development of auricle at sixth week of gestation.

b) This case describes a 51-year-old gentleman who presented with a huge, soft and painless swelling over left parotid region which was progressively increasing in size over two years. Clinical and ultrasonographical findings favour the diagnosis of parotid tumour.

c) The diagnosis of preauricular sinus was made only upon excision of the mass under general anaesthesia. Post operatively, the recovery was good and there was no complication.

d) Though it is extremely rare, preauricular sinus should be considered as a differential diagnosis of painless soft parotid swelling.

\section{References}

1. Heusinger HK (1864) Fisteln von Noch Nicht Beobachteter Form. Virchows Arch 29: 358-380.

2. Currie AR, King WW, Vlantis AC, Li AK (1996) Pitfalls in the management of preauricular sinuses. Br J Surg 83(12): 1722-1724.

3. Scheinfeld NS, Silverberg NB, Weinberg JM, Nozad V (2004) the preauricular sinus: a review of its clinical presentation, treatment and associations. Pediatr Dermatol 21(3): 191-196.

4. Gan EC, Anicete R, Tan HK, Balakrishnan A (2013) Preauricular sinuses in the pediatric population: Techniques and recurrence rates. Int $\mathrm{J}$ of Pediatr Otorhinolaryngol 77(3): 372-378.

5. Baatenburg de Jong RJ (2005) A new surgical technique for treatment of preauricular sinus. Surgery 137(5): 567-570. 


$\begin{array}{ll}\text { BIOMEDICAL } & \begin{array}{l}\text { Assets of Publishing with us } \\ \text { RESEARCHES }\end{array} \\ \text { - Global archiving of articles } \\ \text { - Immediate, unrestricted online access }\end{array}$

